\title{
Urolitíase em felinos: abordagem terapêutica ou cirúrgica?
}

A urolitíase é uma das principais causas de formações de cálculos no trato urinário dos animais domésticos e refere-se ao fato de haver cálculos ou urólitos nos rins, ureter, bexiga ou uretra. No presente estudo, utilizou-se o método de revisão de literatura, que tem a finalidade de reunir e sintetizar resultados de pesquisas sobre determinado tema ou questão, contribuindo para o aprofundamento do conhecimento do tema investigado, visto que possibilita sumarizar as pesquisas já concluídas e obter conclusões a partir de um tema de interesse. A formação dos urólitos está relacionada a fatores dietéticos e não dietéticos. Entre os fatores não dietéticos estão à raça, idade, infecção do trato urinário e sexo. A composição da dieta pode interferir tanto no aparecimento quanto na prevenção de recidivas de urolitíases, já que a mesma afeta a densidade específica, o volume e o pH urinário. A visualização de urólitos não deve ser encarada como o diagnóstico final, pois a litíase é considerada consequência de outras enfermidades. Sendo assim, é imperativo investigar a causa de base. Por se tratar de uma enfermidade com alta prevalência e recidivas frequentes, o conhecimento de técnicas de tratamento menos invasivas por parte do médico veterinário torna-se extremamente benéfico para os pacientes, aumentando a qualidade de vida, por ser menos traumáticas. Cabe ao médico veterinário escolher o método de tratamento mais adequado a cada caso.

Palavras-chave: Cistólitos; Felinos; Trato urinário; Urólitos

\section{Urolithiasis in felines: therapeutic or surgical approach?}

Urolithiasis is a major cause of stone formation in the urinary tract of domestic animals and refers to the fact that there are stones or uroliths in the kidneys, ureter, bladder or urethra. In the present study, the literature review method was used, which aims to gather and synthesize research results on a given topic or issue, contributing to the deepening of knowledge of the investigated topic, since it allows summarizing the researches already concluded and draw conclusions from a topic of interest. The formation of uroliths is related to dietary and non-dietary factors. Non-dietary factors include race, age, urinary tract infection and sex. The composition of the diet can interfere both in the appearance and in the prevention of recurrences of urolithiasis, since it affects the specific density, volume and urinary $\mathrm{pH}$. The visualization of uroliths should not be seen as the final diagnosis, as lithiasis is considered a consequence of other diseases Therefore, it is imperative to investigate the underlying cause. As it is a disease with high prevalence and frequent relapses, the knowledge of less invasive treatment techniques by the veterinarian becomes extremely beneficial for patients, increasing the quality of life, as it is less traumatic. It is up to the veterinarian to choose the most appropriate treatment method for each case.

Keywords: Cystolites; Cats; Urinary tract; Uroliths

Topic: Biologia Comparada

Reviewed anonymously in the process of blind peer.
Received: $10 / 02 / 2021$

Approved: 20/03/2021

Bruna Vaz da Silva Gonçalves (iD)

Universidade Tuiuti do Paraná, Brasil

http://lattes.cnpq.br/9650391763326837

http://orcid.org/0000-0002-7880-2682

bruvazlain@gmail.com

Isis Regina Barberini (iD

Universidade Tuiuti do Paraná, Brasil

http://lattes.cnpq.br/9482075645403205

http://orcid.org/0000-0003-1939-7194

isisreginab18@gmail.com

Silvana Krychak Furtado (iD)

Universidade Tuiuti do Paraná, Brasil

http://lattes.cnpq.br/8101364738483981

http://orcid.org/0000-0002-7192-349X

silvana.krychak@utp.br

\section{Referencing this:}

GONÇALVES, B. V. S.; BARBERINI, I. R.; FURTADO, S. K.. Urolitíase em felinos: abordagem terapêutica ou cirúrgica? Scire Salutis, v.11, n.2, p.1-13, 2021. DOI: http://doi.org/10.6008/CBPC2236-

DOI: 10.6008/CBPC2236-9600.2021.002.0001 $\underline{9600.2021 .002 .0001}$ 


\section{INTRODUÇÃO}

As doenças do trato urinário estão entre as enfermidades mais observadas na clínica de pequenos animais e dentre elas, destaca-se a urolitíase. É uma enfermidade que acomete humanos, felinos, caninos, entre outras espécies. Como as alterações que a doença ocasiona não se limitam exclusivamente ao trato urinário, apresenta grande relevância clínica. O sistema urinário dos animais domésticos tem a habilidade de formar urina concentrada, sendo uma de suas funções a eliminação dos resíduos corporais na forma líquida (SENIOR et al., 1986). Quando a urina se torna supersaturada com sais dissolvidos, estes podem precipitar-se para formar cristais. Se estes cristais não forem excretados, podem agregar-se em concreções sólidas, conhecidas então como cálculos.

A urolitíase é uma das principais causas de formações de cálculos no trato urinário dos animais domésticos e refere-se ao fato de haver cálculos ou urólitos nos rins, ureter, bexiga ou uretra (FOSSUM, 2014). A formação dos urólitos está relacionada a fatores dietéticos e não dietéticos. Entre os fatores não dietéticos estão: a raça, idade, infecção do trato urinário e sexo. A composição da dieta pode interferir tanto no aparecimento quanto na prevenção de recidivas de urolitíases, já que a mesma afeta a densidade específica, o volume e o pH urinário (CARCIOFI, 2007). Independente do processo de formação, os urólitos são caracterizados pelo potencial de alterar a fisiologia do trato urinário (ETTINGER et al., 2004). A visualização de urólitos não deve ser encarada como o diagnóstico final, pois a litíase é considerada consequência de outras enfermidades. Sendo assim, é imperativo investigar a causa de base (LANGSTON et al., 2008).

A investigação e a terapêutica devem ser fundamentadas e direcionadas considerando a composição do cálculo, que é determinada por técnicas de análise quantitativas e qualitativas (LULICH et al., 2016). A recuperação de pedras por abordagem cirúrgica foi considerada por muitos anos como uma das únicas opções relacionadas ao tratamento. Atualmente, sabe-se que é possível dissolver alguns tipos de urólitos, sem necessidade de cirurgia (LANGSTON et al., 2010; LULICH et al., 2016). Apesar disso, ainda há certa relutância em instituir a terapia clínica na rotina da medicina de animais de companhia (LULICH et al., 2009). Diversos estudos têm demonstrado a eficiência do uso de dieta e/ou medicamentos para manejo dos urólitos, com protocolos semelhantes aos utilizados em humanos (SINGH et al., 2011; HENDERSON et al., 2017).

Além da terapêutica clínica, têm-se desenvolvido alternativas minimamente invasivas com menores riscos de complicações quando comparadas as abordagens cirúrgicas convencionais, sobretudo quando não há possibilidade ou recomendação de dissolução. Diante dos riscos inerentes à urolitíase e seu tratamento, é fundamental considerar alternativas menos invasivas e comunicar aos tutores sobre todas as opções terapêuticas e riscos associados (LULICH et al., 2016). Aproximadamente $13 \%$ das causas de afecções do trato urinário em felinos é urolitíase e a prevalência da enfermidade na espécie felina situa-se entre 15\% a 23\% nos pacientes com doença do trato urinário inferior (GERBER et al., 2005; LEKCHAROENSUK et al., 2001). Com relação ao sexo a incidência de urolitíase parece ser igual entre eles, enquanto que as suas manifestações clínicas divergem, pois, a obstrução uretral é comum no macho e a cistite e a uretrite na 
fêmea. É entre os sete e nove anos de idade que os gatos apresentam maior risco de desenvolver cálculos de oxalato de cálcio. Gatos mais jovens apresentam mais casos de cálculos por estruvita (GERBER et al., 2005).

Os gatos que vivem dentro de casa apresentam maior predisposição para a doença do que aqueles que vivem soltos fora de casa. Aproximadamente 30 a 70\% dos gatos acometidos por um episódio de inflamação do trato urinário inferior apresentarão recidivas (GRAUER, 2015). Com base na análise exposta a presente revisão tem por escopo apresentar um estudo sobre os principais urólitos que acometem os felinos e suas possibilidades terapêuticas e/ou cirúrgicas.

\section{METODOLOGIA}

No presente estudo, utilizou-se o método de revisão de literatura, que tem a finalidade de reunir e sintetizar resultados de pesquisas sobre determinado tema ou questão, contribuindo para o aprofundamento do conhecimento do tema investigado, visto que possibilita sumarizar as pesquisas já concluídas e obter conclusões a partir de um tema de interesse. O levantamento bibliográfico desta revisão foi realizado por meio de busca por artigos científicos encontrados em bancos de dados em geral, como o Google Acadêmicos, Elsevier etc.

Os critérios de inclusão utilizados para a seleção da amostragem foram: textos disponibilizados na íntegra, através de acesso as bases de dados; e atendimento à análise das variáveis contempladas para o estudo (medidas de avaliação). As publicações mais condizentes foram selecionadas, incluídas por título e resumo, logo, feita uma leitura íntegra para posteriormente ser selecionado ou excluído. Selecionou-se 63 fontes para o presente estudo. Foram selecionadas fontes que apresentaram os seguintes descritores e/ou palavras chaves: Urolitíase, doenças do trato gastrointestinal, urólitos e cálculos sendo essas palavras chaves focadas no âmbito de felinos.

\section{DISCUSSÃO TEÓRICA}

Os urólitos são classificados de acordo com a composição dos cristais. Conhecer a composição do urólito é importante, já que os métodos modernos de detecção, tratamento e prevenção são baseados principalmente nessas informações (KAUFMANN et al., 2011). De acordo com o tipo mineral os mais comumente observados são os urólitos de estruvita, também conhecido como fosfato amônio magnesiano e os de oxalato de cálcio (monohidratado e diidratado), representando cerca de $80 \%$ a $90 \%$ das ocorrências clínicas (BARTGES et al, 2015). Ainda podem ser encontrados urólitos de urato (urato amônio, ácido úrico ou sais de urato) e, mais raramente, os de xantina, fosfato de cálcio, cistina e sílica (OSBORNE et al., 2009; HOUSTON et al., 2009; HOUSTON et al., 2016; CANNON et al., 2007).

O diagnóstico de urolitíase é baseado no histórico do animal, no exame físico (LANGSTON et al., 2008) nos achados dos exames complementares laboratoriais e nos exames radiográficos e/ou ultrassonográficos (LANGSTON et al., 2008; BARTGES et al., 2015). A apresentação clínica da doença varia conforme a localização, número e tamanho dos cálculos, independente da composição (GRAUER, 2015a). 
Entretanto, os sinais clínicos mais comumente observados são hematúria, polaquiúria, disúria, estrangúria, incontinência urinária e micção em local inapropriado (LANGSTON et al., 2008).

O histórico clínico pode revelar presença de doenças do trato urinário anterior à manifestação, doença metabólica pré-existente ou o paciente pode não apresentar histórico de qualquer alteração (BARTGES et al., 2015). A urolitíase pode levar a um quadro de obstrução uretral parcial ou total, principalmente em machos (GRAUER, 2015; LANGSTON et al., 2008) alterando o fluxo urinário, o que ocasiona distensão da bexiga vesical, disúria e dor abdominal intensa (BARTGES et al., 2004). O paciente pode ainda apresentar estrangúria, como também depressão, anorexia e vômito decorrente de uremia pósrenal e ocasionalmente, ruptura vesical, resultando em uroabdomen (LANGSTON et al., 2008).

A realização de perfil bioquímico completo e a contagem de células sanguíneas devem ser realizadas sempre que tenha suspeita ou confirmação de urolitíase e podem estar normais (LANGSTON et al., 2008; BARTGES et al, 2015). Azotemia, hiperfosfatemia e hiperpotassemia podem estar presentes também quando há obstrução do trato urinário superior e/ou inferior (LANGSTON et al., 2008). Algumas alterações laboratoriais podem sugerir um determinado tipo de urólito, como uma associação de hipercalcemia com oxalato de cálcio ou fosfato de cálcio (LANGSTON et al., 2008; MIDKIFF et al., 2000; GISSELMAN et al., 2009). Em pacientes com suspeita de doenças no trato urinário, o exame de urina é uma parte importante da avaliação diagnóstica. Cristalúria é um achado relevante, embora a solubilidade do cristal seja afetada pelo pH urinário (LANGSTON et al., 2008;).

Urólitos de estruvita são mais prováveis de se formar em urina alcalina; fosfato de cálcio em urina alcalina para neutra; oxalato de cálcio e sílica em neutro para ácida; urato, xantina, cistina e brushita em urina ácida (BARTGES, et al., 2004). Os exames de imagem são parte fundamental para a definição do diagnóstico da urolitíase, pois além de detectar urólitos, determinam a localização, o tamanho, densidade, formato e o número de cálculos (BARTGES, 2016). A radiografia é útil para a detecção de cálculos radiopacos tais como os de fosfato de cálcio, oxalato de cálcio, estruvita e sílica. Por outro lado, os cálculos de urato de amônio frequentemente são radiolucentes, mas podem apresentar a camada mais externa radiopaca, o que facilita a sua visualização pelo exame simples (LULICH, et al., 2011).

\section{Urolitíase de Estruvita}

A estruvita é um composto de minerais encontrado nos urólitos de gatos, sendo formada por magnésio, amônio e fosfato. O mecanismo para formação dos urólitos de estruvita pode estar relacionado com a presença de infecção do trato urinário (ITU), fatores metabólicos e dietéticos (GRAUER, 2015). Em felinos normalmente ocorre sem ITU, sendo denominados urólitos de estruvita estéreis, se diferem dos cães que são mais predispostos a ter urolitíase de estruvita induzida por infecção com bactérias produtoras de uréase (LEKCHAROENSUK et al., 2001).

A dieta pode favorecer a formação de cálculos quando associada ao consumo excessivo de ração, o que resultaria em obesidade e maior excreção de minerais calculogênicos na urina (PALMA et al., 2009). Outra possibilidade, é a alta concentração de magnésio, fósforo, cálcio, sódio, cloro e fibras e com 
moderada quantidade de proteína. A alimentação também favorece a formação de pH urinário alcalino. Foi demonstrado que em condições onde pH urinário está constantemente elevado $(6,5$ a 6,9 versus 6,0 a 6,2) a chance para formação de urólitos de estruvita era duas vezes maior (LEKCHAROENSUK et al., 2001). O aumento do $\mathrm{pH}$ é comumente afetado pela dieta mas pode estar associado com terapia por drogas e desordem tubular renal (GRAUER, 2015).

Entre outros fatores que influenciam na formação de urólitos em felinos sem ITU, pode-se citar: maior capacidade para concentrar urina (quando comparado aos cães) e, portanto, maior supersaturação urinária, baixa ingestão de água e consequentemente diminuição na frequência de micção (GRAUER, 2015). Os pacientes que apresentam urolitíase por estruvita se caracteriza pela tendência a ter menos de um ano ou mais de 10 anos de idade (PALMA, et al., 2009). O risco para formação tende a diminuir após os 10 anos de idade e com relação ao sexo, a doença parece afetar igualmente machos e fêmeas (BARTGES et al., 2015) embora alguns estudos demonstrem risco maior nas fêmeas (CANNON et al., 2007; LEKCHAROENSUK et al., 2000).

As raças mais acometidas por esse tipo mineral são os Himalaios, Persas e o gato doméstico comum (HOUSTON et al., 2009; HOUSTON et al., 2016). Pacientes felinos em que os mecanismos de defesa estão alterados e fatores do hospedeiro comprometidos (anomalias congênitas, neoplasias), uretrostomias perineais ou sondas urinárias de demora (MOORE, 2007), DRC, hipertireoidismo e diabetes mellitus, também apresentam maior risco (BAILIFF et al., 2008). Os cálculos compostos de estruvita são passíveis de dissolução, tanto os que são causados por ITU, quanto àqueles que estão relacionados ao tipo de alimento consumido pelo animal.

Deve-se sempre considerar a dissolução nesse caso antes da remoção cirúrgica. O tratamento para esse tipo de pedra pode ser realizado mediante terapia nutricional e medicamentosa (LULICH et al., 2016). No entanto, muitas vezes há relutância dos clínicos em tentar esse tipo de tratamento. Embora os sinais clínicos e parâmetros urinários possam ser resolvidos rapidamente após início da terapia dietética de dissolução, é importante que a terapia seja mantida até a completa dissolução dos cálculos (BAHADOR et al., 2014). A necessidade de incluir antibioticoterapia ao protocolo de tratamento se restringe basicamente à espécie canina, que tendem a desenvolver os cálculos de estruvita em decorrência de ITU. Bactérias envolvidas são em geral urease positivas, como Staphylococcus spp, sendo observado principalmente nas fêmeas caninas (OSBORNE et al., 2009; HOUSTON et al., 2011).

Nos casos de cálculos de estruvita não associados à ITU, a dieta tende a ser suficiente para dissolução, após duas a cinco semanas de uso (HOUSTON et al., 2011; LULICH et al., 2016). Em estudo, acompanhando felinos com urocistólitos de estruvita, observou-se redução de $50 \%$ no tamanho das pedras ao utilizar dietas de dissolução e de prevenção. A dissolução completa ocorreu entre 13 e 27 dias (LULICH et al., 2016). Recomenda-se continuidade do uso de dietas calculolíticas por um mês após resolução radiográfica aparente, para que cálculos muito pequenos e não detectados radiograficamente sejam dissolvidos (STURGUESS, 2009). Para os urólitos de estruvita estéreis, a modificação dietética com o uso de ração úmida com menor quantidade de proteína de alta qualidade e redução nas concentrações de fósforo 
e magnésio, induz à acidúria (OSBORNE et al., 2009; ROUDEBUSH et al., 2010), produzindo pH urinário inferior a 6,833.

A dissolução desses urólitos, portanto, pode ser alcançada com uso de dieta de alta umidade que produza pH menor que 6,8 (CALABRO et al., 2011). Essa dissolução é alcançada mais rapidamente quando o $\mathrm{pH}$ urinário esperado pelo uso da dieta é mais ácido. Por exemplo, foi realizado estudo comparando o uso de duas dietas felinas para dissolução de cálculos de estruvita com valores diversos de pH urinário esperado. A primeira dieta, que tinha como objetivo reduzir o pH urinário a valores entre 5,9 e 6,2, dissolveu os urólitos, em média, após 13 dias. A segunda dieta tinha como objetivo a manutenção do pH urinário entre 6,2 e 6,4 e a dissolução foi obtida, em média, 27 dias após o início do tratamento (LULICH et al., 2013).

Acidificantes não devem ser utilizados em conjunto com dietas que promovem a acidificação urinária (CALABRO et al., 2011). Outro fator importante no tratamento faz referência a maior ingestão de água e aumento da frequência de micção, o que colabora com a diminuição das concentrações de substâncias calculogênicas na urina (LULICH et al., 2011). Uma forma de otimizar a ingestão de água pelo paciente felino, é fornecendo rações úmidas ou com maior taxa de umidade ou acrescentando água no alimento seco (LULICH et al., 2016; ULRICH et al., 2009). A eficiência de dietas para a dissolução de estruvita está comprovada; porém, o sucesso da terapia dependerá da predição correta da composição dos cálculos presentes, que pode ser estimada pela identificação da cristalúria, do $\mathrm{pH}$ urinário e características radiográficas.

Quando a dissolução não é alcançada, deve-se considerar a possibilidade de presença de cálculos com outra composição (LULICH et al., 2013). A estruvita, também conhecida como fosfato amônio magnesiano foi por muito tempo o principal mineral encontrado nos cálculos de felinos, entretanto, a sua prevalência sofreu várias alterações e atualmente ela é observada em mesma proporção que os urólitos de oxalato de cálcio (HOUSTON et al., 2016).

\section{Urolitíase de Oxalato de Cálcio}

O mecanismo exato para sua formação ainda é desconhecido, mas fatores como aumento da excreção urinária de cálcio e/ou de oxalato e acidúria parecem interferir (PALM et al., 2011). Foi descrito que a origem dos urólitos de oxalato se relaciona à hipercalciúria, geralmente em decorrência da hipercalcemia secundária a distúrbios metabólicos como hiperparatireoidismo primário, síndrome paraneoplásica e hipercalcemia idiopática em gatos, ou mesmo em situações de normocalcemia (PALM et al., 2011; BARTGES et al., 2015).

Foi demonstrado que cerca de $35 \%$ dos pacientes felinos que apresentaram urolitíase por oxalato de cálcio, apresentavam hipercalcemia idiopática (MIDKIFF, et al., 2000), constituindo fator importante no desenvolvimento da doença. É o principal cálculo observado nas análises de nefrólitos e ureterólitos (PALM et al., 2011), entretanto podem ser encontrados em qualquer segmento do trato urinário (OSBORNE et al., 2011). Outro fator que contribui para a formação de cálculos de oxalato de cálcio é a hiperoxalúria. $O$ ácido 
oxálico é o produto final da metabolização do ácido ascórbico e de outros aminoácidos (glicina e serina) pelo fígado ou do uso de dietas ricas em proteínas (BARTGES et al., 2015). Dessa forma, tanto o aumento na ingestão dietética ou produção endógena pode resultar em hiperoxalúria (GRAUER, 2015). O ácido oxálico forma sais solúveis com íons de sódio e potássio, entretanto com o cálcio, forma um sal relativamente insolúvel (BARTGES, 2016). Portanto, qualquer aumento na concentração urinária de ácido oxálico pode promover a formação de oxalato de cálcio (BARTGES et al., 2015).

Assim como os cálculos de estruvita, a alimentação também influencia no desenvolvimento de urólitos de oxalato de cálcio. Animais alimentados com dietas com baixo sódio ou potássio ou aquelas formuladas para maximizar a acidificação da urina são fatores de risco (LEKCHAROENSUK, et al., 2001; KIRK et al., 1995). A solubilidade do oxalato de cálcio sofre influência do pH da urina (GRAUER, 2015; RATKALKAR et al., 2011). Alimentos que produzem pH urinário entre 6 e 6,2 são três vezes mais prováveis de produzir cálculos de oxalato de cálcio quando comparados com os que produzem pH entre 6,5 e 6,913. Foi verificado que gatos saudáveis alimentados com dietas semelhantes, diferindo apenas em suas propriedades acidificantes ou alcalinizantes, a saturação urinária com oxalato de cálcio era menor quando o pH da urina era maior que 7,2 e maior quando o pH da urina era inferior a 6,533.

Acredita-se que o uso de dietas acidificantes seja o principal fator para formação de urólitos de oxalato de cálcio na espécie felina (OSBORNE et al., 2011), pois foi durante o uso de dietas acidificantes visando tratar e prevenir urólitos de estruvita, que se observou aumento na ocorrência de urólitos de oxalato de cálcio (PICAVET et al., 2007). A acidúria persistente pode estar associada a acidose metabólica de baixo grau, que promove a mobilização óssea e aumenta a excreção urinária de cálcio e diminui a excreção urinária de citrato (GRAUER, 2015).

No entanto, este efeito não foi relatado em estudos de gatos de até um ano de idade (BARTGES et al., 2013). Em uma série de casos de cinco gatos com hipercalcemia e cálculos de oxalato de cálcio (THUMCHAl et al., 1996), a descontinuação de dietas acidificantes ou de medicações acidificantes urinários foi associada à normalização da concentração sérica de cálcio. Com relação à predisposição para esse tipo mineral, os machos desenvolvem mais facilmente urólitos de oxalato de cálcio principalmente quando castrados (LEKCHAROENSUK et al., 2000; PALM et al., 2011). Foi demonstrado que os gatos domésticos de pelo curto, médio e longo apresentaram 1,4 vezes mais chances de desenvolver essa forma de urolitíase (HOUSTON et al, 2009). Também se verificou que tanto machos quanto fêmeas das raças Persa, Himalaio, Birmanês e Ragdoll apresentaram maior risco (LEKCHAROENSUK et al., 2000).

Alguns estudos demonstram ocorrência ainda no Havana Brown, British Shorthair, Foreign Shorthair, Scottish Fold e Exotic Shorthair (HESSE et al., 2012). Ocorre mais comumente em animais de meia-idade a idosos (BARTGES, et al., 2004), entre cinco a 12 anos (GRAUER, 2015). A recidiva de cálculos de oxalato de cálcio em gatos é um problema potencial (LULICH, et al., 2011). Os cálculos de oxalato de cálcio, diferente dos de estruvita não são passíveis de dissolução. Protocolos para dissolução desse tipo de litíase urinária não foram desenvolvidos, pois o mecanismo exato na formação desses cálculos não é completamente entendido. Nesses casos, a recuperação por meio de cirurgia acaba sendo um dos métodos 
de escolha (STURGUESS, 2009; PALM et al., 2011; RADITIC, 2015). O manejo nutricional profilático é realizado para evitar recidivas.

Cálculos de oxalato de cálcio possuem variados fatores de risco, o que dificulta a terapia e adoção de medidas preventivas eficientes (RADITIC, 2015). As taxas de recorrência desse tipo de urólito são descritas em $50 \%$ após dois anos, mas podem ser reduzidas pelo fornecimento de dieta não acidificante com alto nível de umidade e sem excesso de cálcio, oxalato e proteína. Dietas secas, acidificantes e com altas concentrações de vitaminas C ou D, ou cálcio e petiscos devem ser evitada (STURGESS, 2009). Como a urolitíase por oxalato de cálcio está associada a pH ácido, dietas contendo acidificantes como ácido fosfórico, cloreto de amônio ou metionina são fator de risco para a formação desses cálculos em felinos (DIJCKER et al., 2011; OKAFOR et al., 2014).

Felinos com urólitos de oxalato de cálcio alimentados com dieta com alto teor de umidade $(77,4 \%$ a $81,2 \%)$ tiveram menor probabilidade de desenvolver recidivas, quando comparado com animais alimentados com dieta com pouca umidade (7,0\% a 7,9\%) (LEKCHAROENSUK, et al., 2001). Se houver cálculos presumivelmente formados por oxalato de cálcio, não associados à obstrução do fluxo urinário, infecção recorrente ou deterioração da função renal, pode-se optar por monitorar a atividade e selecionar protocolos que minimizem o crescimento do cálculo (KOEHLER et al., 2008).

\section{Urolitíase por Urato}

Os urólitos de urato provêm do metabolismo das purinas, sendo transportadas ao fígado e metabolizadas dentro do hepatócito pela enzima uricase, que as convertem em alantoína, esse sendo um composto nitrogenado altamente solúvel (BANNASCH et al, 2009). As purinas são de produção endógena resultantes do metabolismo das proteínas e degradação do DNA/RNA, além de estarem presentes na dieta (STURGUESS, 2009). O mecanismo exato para a ocorrência de urólitos de urato em felinos, ainda não está totalmente esclarecido.

Mas fatores como hiperuricosúria, hiperamonúria e acidúria são considerados de risco (OSBORNE et al., 1995; MCCUE et al., 2009) Doenças hepáticas graves e desvio portossistêmico podem resultar nessas alterações e posterior formação de cálculos (APPEL et al., 2010; DEAR et al., 2011). Contudo em felinos as causas de hiperuricosúria e formação de urólitos de urato ainda permanecem idiopáticas (LULICH et al., 2016; ALBASAN et al., 2012). Os urólitos de urato são menos comuns em felinos quanto àqueles compostos por estruvita e oxalato de cálcio, entretanto, são considerados o terceiro tipo mineral mais comum na espécie, representando de 3\% a 10\% das amostras analisadas (HOUSTON et al., 2016).

Em animais com menos de um ano de idade, parece ser o segundo tipo mineral mais comum, estando atrás somente da estruvita (BARTGES et al., 2015). As raças Siâmes (CANNON et al., 2007), Mau egípcio e Birmânes aparecem como predispostas (APPEL et al., 2010; DEAR et al., 2011). Em estudo realizado no Canadá, foi relado aumento na frequência de cálculos de urato na raça Mau Egípcio (HOUSTON et al, 2009), com maior ocorrência em machos (APPEL et al., 2010). Dietas com alto teor de purinas podem favorecer a formação desse tipo de urólito (MCCUE et al., 2009), pois ocasionam maior 
excreção renal de sais de urato com consequente acidificação do pH urinário, promovendo menor solubilidade dos cristais (RATKALKAR et al., 2011; ALBASAN et al., 2012).

A produção de urina alcalina auxilia na prevenção desse tipo de pedra por meio do aumento da solubilidade do ácido úrico e diminuição da produção de íons amônio (LULICH et al., 2016). Protocolos para dissolução de urólitos de urato não foram desenvolvidos para pacientes felinos; o alopurinol, utilizado em cães, é contraindicado na espécie. Todavia deve-se preconizar como medidas preventivas, a administração de dietas com baixa quantidade de precursores de purinas e o uso de alcalinizantes urinários, visando um pH superior à 7,017, (MCCUE et al., 2009).

\section{Urolitíase por Xantina}

Os urólitos de xantina, assim como os de urato, também são derivados do metabolismo das purinas. Proveniente da hipoxantina, que por ação da enzima xantina oxidase é convertida em xantina (OSBORNE et al., 2009), a qual é o metabólito menos solúvel. Este tipo de urolitíase é raro em felinos (ÁNGEL et al., 2012). O principal fator de risco para o desenvolvimento de urólitos de xantina, é a xantinúria. Que pode apresentar-se de forma primária ou secundária (OSBORNE et al., 2009; ÁNGEL et al., 2012).

A xantinúria primária pode ser proveniente de um defeito na enzima xantina dehidrogenase (xantina oxidase), o que acarreta no aumento nas concentrações de xantina e hipoxantina e diminuição das concentrações de ácido úrico no sangue e na urina (ÁNGEL et al., 2012). Em relatos (MESTRINHO et al., 2013; FURMAN et al., 2015) de casos de felinos com urólitos de xantina, concluiu-se que os pacientes apresentavam a forma primária. Visto que não tinham histórico de tratamento com alopurinol e quando dosados os níveis de hipoxantina e xantina urinária e sérica e comparados ao grupo controle, esses se encontravam aumentados. Em um dos relatos, o paciente apresentava menos de um ano de idade (MESTRINHO et al., 2013).

A forma secundária da xantinúria é a mais comum e decorre normalmente do uso de alopurinol, principalmente em cães, como forma de tratamento para leishmaniose ou urolitíase por urato (OSBORNE et al., 2009). Como protocolos médicos não foram desenvolvidos para dissolver este tipo de pedra é necessário extrair cirurgicamente. Isto é essencial para determinar a composição dos urólitos e entender a fisiopatologia, determinar o tratamento apropriado e prevenção da recorrência do problema (ÁNGEL et al., 2010). A prevenção envolve o uso de dieta alcalinizante e com restrição de proteínas. Sem medidas preventivas, os cálculos de xantina geralmente se recidivam dentro de 3 a 12 meses após a remoção (BARTGES et al., 2015).

\section{Urolitíase de Fosfato de Cálcio}

Os urólitos de fosfato de cálcio são compostos normalmente por brushita, carbonato apatita e hidroxiapatita (HOUSTON et al., 2016; ULRICH et al., 2009), sendo as duas últimas as formas mais comuns em felinos (MOORE, 2007). Fosfato de cálcio é um tipo de cálculo encontrado raramente em sua forma 
pura, com menos de 1\% para cães e gatos (HOUSTON et al., 2009). Normalmente quando observado, está associado à urólitos de estruvita e oxalato de cálcio, (TION et al., 2015) principalmente sob a forma de hidroxiapatita (OSBORNE et al., 1995).

Os cálculos compostos por esse tipo mineral, normalmente são pequenos, múltiplos e de formato arredondado e/ou cuboide (LULICH, et al., 2011). Os fatores que contribuem para a formação desse tipo de pedra incluem: hipercalciúria, excesso de cálcio e vitamina $D$ na dieta, além de hiperfosfatúria, por excesso no consumo de fósforo, pH urinário alcalino e diminuição no volume de urina (RATKALKAR et al., 2011; TION et al., 2015). Os cálculos de fosfato de cálcio podem se dissolver espontaneamente quando associados com hipercalcemia de causa identificável, caso contrário é necessário cirurgia. Nos casos em que não se identifica a causa, o manejo dietético é semelhante ao dos cálculos de oxalato de cálcio (STURGUESS, 2009).

\section{Urolitíase de Sílica}

Os urólitos compostos de sílica possuem coloração branco-acinzentado e são encontrados normalmente em bexiga e uretra. Possuem formato esférico com pontas rombas (LULICH, et al., 2011). Esse tipo de urolitíase apresenta pouca ocorrência em cães e menos ainda em gatos (HOUSTON et al., 2016; LULICH et al., 2011).

A formação de urólitos de sílica está associada com a ingestão de altas quantidades de silicato, na dieta (fontes de proteína vegetal, como casca de arroz e de soja) (ULRICH et al., 2009) ou na água (ÁNGEL et al., 2010), o que leva ao aumento na excreção urinária de sílica (OSBORNE et al., 2009). Com relação à dissolução de cálculos de sílica, protocolos não foram desenvolvidos, entretanto, fatores profiláticos baseiam-se na lógica de evitar a ingestão de silicato (ULRICH et al., 2009).

\section{Urolitíase de Cistina}

O principal fator de risco para a formação de urólitos de cistina é a presença de cistinúria, associada a defeito na reabsorção tubular renal de cistina e outros aminoácidos, como ornitina, lisina e arginina, o que resulta no acúmulo na urina. A cistina é o aminoácido menos solúvel, portanto o que se precipita com maior facilidade (PALACIN et al., 2013). Em gatos, a cistinúria e formação de urólitos de cistina são raros, representando cerca de $0,1 \%$ dos urólitos nos Estados Unidos e Canadá.

O primeiro relato de cistinúria em felinos foi publicado em 1991. Mas somente no ano de 2015 que se verificou cistinúria associada à mutação do gene SLC3A156. Em 2016 foram descritos nos Estados Unidos casos de cinco felinos com mutações no gene SLC7A957. Cistinúria associada à mutação no gene SLC7A9 também foi observada em dois felinos na Alemanha (HILTON et al., 2017), embora somente um deles apresentasse cálculo. Para tratamento desse tipo de urolitíase, a alcalinização urinária ajuda na solubilidade dos cristais de cistina, com o uso de drogas alcalinizantes, deve se preconizar um pH urinário de cerca de 7,210 .

O fármaco N-(2-mercaptopropionil)-glicina (2-MPG) pode ser usado para prevenção, entretanto, 
somente com o uso de dietas reduzidas em proteínas, especialmente metionina, já se tem boa resposta. A restrição proteica deve ser instituída com precaução em felinos, pois a espécie apresenta maiores necessidades orgânicas de proteína (LULICH et al., 2016). Com o desenvolvimento de novas tecnologias para manejo das urolitíases, a remoção cirúrgica deixou de ser a primeira opção em muitos casos (LULICH et al., 2009; LANGSTON et al., 2010; SINGH et al., 2011). Existem métodos minimamente invasivos para recuperação dos cálculos urinários, como a urohidropropulsão, para os localizados em trato urinário inferior. Também é possível a utilização de técnicas como cistoscopia transuretral com ou sem uso de litotripsia por laser (BARTGES et al, 2015; LULICH et al., 2016).

Entretanto, existem limitações nas técnicas, desse modo a escolha do procedimento minimamente invasivo deve ser considerada dependendo do tipo de urólito, características do paciente, experiência do operador e disponibilidade de equipamento (LANGSTON et al., 2010; LULICH et al., 2016). Procedimentos que não necessitam incisão e/ou minimamente invasivos estão associados à hospitalização mais curta, diminuição no tempo de anestesia e recuperação mais rápida do paciente, além de apresentar menores taxas de recidiva em comparação com a cistotomia cirúrgica (LULICH et al., 2009; WEBB et al., 2014; LULICH et al., 2016).

\section{CONCLUSÕES}

Ao considerar que a urolitíase é uma doença com diversas causas, ressalta-se a importância da investigação desses fatores para adequado tratamento e prevenção. Cabe salientar que antes da escolha terapêutica, deve-se determinar a composição da pedra. Nos casos em que não é possível obter o cálculo ou fragmentos, predizer os componentes auxilia na definição do tratamento. Compreender os fatores de risco relacionados ao animal em conjunto com alterações observadas em exames laboratoriais e de imagem, colaboram para instituir terapias de dissolução dos urólitos, evitando submeter o paciente a procedimentos cirúrgicos e anestésicos e diminuindo as complicações pós-cirúrgicas.

Com as informações contidas no presente trabalho, pode-se afirmar que a nutrição, quando bem administrada, possui fundamental importância no tratamento e na prevenção das urolitíases, proporcionando melhor qualidade de vida aos animais. Por se tratar de uma enfermidade com alta prevalência e recidivas frequentes, o conhecimento de técnicas de tratamento menos invasivas por parte do médico veterinário torna-se extremamente benéfico para os pacientes, aumentando a qualidade de vida, por ser menos traumáticas. Cabe ao médico veterinário escolher o método de tratamento mais adequado a cada caso.

\section{REFERÊNCIAS}

ALBASAN, H.; OSBORNE, C.; LULICH, J.; LEKCHAROENSUK, C.. Risk factors for urate uroliths in cats. J Am Vet Med Assoc, v.240, n.7, p.842-847, 2012.

ÁNGEL, C. J.; DIEZ, P. I.; PEREZ, G. C. C.; GARCIA, R. M. B.. Composition of lower urinary tract stones in canines in Mexico City. Urol. Res., v.38, n.3, p.201-204, 2010.

ÁNGEL, C. J.; PÉREZ, G. C. C.; QUIJANO, H. I. A.; MENDOZA. L.
C. I.; DIEZ, P. I.; MARTINEZ, C. J. S.. Xanthinuria: a rare cause of urolithiasis in the cat. Vet Mex, v.43, n.4, p.317-325, 2012.

APPEL, S. L.; HOUSTON, D. M.; MOORE, A. E.; WEESE, J. S. Feline urate urolithiasis. Can Vet J., v.51, n.5, p.493-496, 2010.

BAHADOR, M. M. B.; TABRIZI, A. S.; KOZACHOK, V. S.. Effects 
of diet on the management of struvite uroliths in dogs and cats. Comparative Clinical Pathology, v.23, n.3, p.557-560, 2014.

BAILIFF, N. L.; WESTROPP, J. L.; NELSON, R. W.; SYKES, J. E.; OWENS, S. D.; KASS, P. H.. Evaluation of urine specific gravity and urine sediment as risk factors for urinary tract infections in cats. Vet Clin Pathol, v.37, n.3, p.317-322, 2008.

BANNASCH, D.; HENTHORN, P. S.. Changing paradigms in diagnosis of inherited defects associated with urolithiasis. Veterinary Clinics of North America: Small Animal Practice, v.39, n.1, p.111-125, 2009.

BARTGES, J. W.; KIRK, C.; LANE, I. F.. Management of calcium oxalate uroliths in dogs and cats. Vet Clin North Am Small Anim Pract, v.34, n.4, p.969-987, 2004.

BARTGES, J. W.; KIRK, C. A.; COX, S. K.; MOYERS, T. D.. Influence of acidifying or alkalinizing diets on bone mineral density and urine relative supersaturation with calcium oxalate and struvite in healthy cats. Am J Vet Res., v.74, n.10, p.1347-1352, 2013.

BARTGES, J. W.; CALLENS, A. J.. Urolithiasis. Veterinary Clinics of North America: small Animal Practice, v.45, n.4, p.747-768, 2015.

BARTGES, J. W.. Feline calcium oxalate urolithiasis: risk factors and rational treatment approaches. J Feline Med Surg., v.18, n.9, p.712-722, 2016.

CALABRO, S.; TUDISCO, R.; BIANCHI, S.; GROSSIL, M.; BONIS, A.; CUTRIGNELLI, M. I.. Management of struvite uroliths in dogs. The British Journal of Nutrition., v.106, n.1 p.191-193, 2011.

CANNON, A. B.; WESTROPP, J. L.; RUBY, A. L.; KASS, P. H.. Evaluation of trends in urolith composition in cats: 5,230 cases (1985-2004). J Am Vet Med Assoc, v.231, n.4, p.570576, 2007.

CARCIOFI, A.. Como a dieta influencia o pH urinário e a formação de cálculos em cães e gatos? In: SIMPÓSIO SOBRE NUTRIÇÃO DE ANIMAIS DE ESTIMAÇÃO. Anais. Campinas: CBNA, 2007.

DEAR, J. D.; SHIRAKI, R.; RUBY, A. L.; WESTROPP, J. L.. Feline urate urolithiasis: a retrospective study of 159 cases. J Feline Med Surg., v.13, n.10, p.725-732, 2011.

DIJCKER, J. C.; PLANTINGA, E. A.; VAN B. J.; HENDRIKS, W. $\mathrm{H}$.. Influence of nutrition on feline calcium oxalate urolithiasis with emphasis on endogenous oxalate synthesis. Nutrition Research Reviews, v.24, n.1, p. 96-110, 2011.

ETTINGER, S.; FELDMAN, E.. Tratado de medicina interna veterinária: doenças do cão e do gato. Rio de Janeiro: Guanabara Koogan, 2004.

FOSSUM, T. W.. Cirurgia de Pequenos Animais. 4 ed. Rio de Janeiro: Elsevier, 2014.

FURMAN, E.; HOOIJBERG, E.; LEIDINGER, J.; ZEDINGER, C.; LEIDINGER, E.; GIGER, U.. Hereditary xanthinuria and urolithiasis in a domestic shorthair cat. Comp Clin Path, v.24, n.6, p. 1325-1329, 2015.

GERBER, B.; BORETTI, F. S.; KLEY, S.; LALUHA, P.; MÜLLER, C.; SIEBER, N.. Evaluation of clinical signs and causes of lower urinary tract disease in European cats. J Small Anim Pract., v.46, n.12, p. 571-577, 2005.

GISSELMAN, K.; LANGSTON, C.; PALMA, D.; MCCUE, J.. Calcium oxalate urolithiasis. Comp ContEduc Vet, v.31, n.11, p.496-502, 2009.
GRAUER, G. F.. Feline struvite \& calcium oxalate urolithiasis. Today's Veterinary Practice, v.5, n.5, p.14-20, 2015.

GRAUER, G. F.. Manifestações clínicas dos distúrbios urinários: urolítiase canina. In: NELSON, A. W.; COUTO, C. G.. Medicina Interna de Pequenos Animais. Rio de Janeiro: Elsevier, 2015.

HENDERSON, C. T.; BUNKERS, J.; CONTRERAS, E. T.; CROSS, E.; LAPPIN, M. R. Use of Purina Pro Plan Veterinary Diet UR Urinary St/Ox to Dissolve Struvite Cystoliths. Topics in Companion Animal Medicine, v.32, n.2, p.49-54, 2017.

HESSE, A.; ORZEKOWSKY, H.; FRENK, M.; NEIGER, R. Epidemiological data of urinary stones in cats between 1981 and 2008. Tierarztl Prax Ausg K Kleintiere Heimtiere, v.40, n.2, p.95-101, 2012.

HILTON, S.; MIZUKAMI, K.; GIGER, U.. Cystinuria caused by a SLC7A9 missense mutation in Siamese-crossbred littermates in Germany. Tierarztl Prax Ausg K Kleintiere Heimtiere, v.45, n.4, p.265-272, 2017.

HOUSTON D. M.; MOORE A. E.. Canine and feline urolithiasis: examination of over 50000 urolith submissions to the Canadian Veterinary Urolith Centre from 1998 to 2008. Can Vet J, v.50, n.12, p.1263-1268, 2009.

HOUSTON, D. M.; WEESE, H. E.; EVASON, M. D.; BIOURGE, V.; VANHOEK, I. A diet with a struvite relative supersaturation less than 1 is effective in dissolving struvite stones in vivo. The British Journal of Nutrition, Cambridge, v.106, n.1, p.90-92, 2011.

HOUSTON, D. M.; VANSTONE, N. P.; MOORE, A. E.; WEESE, H. E.; WEESE, J. S. Evaluation of 21426 feline bladder urolith submissions to the Canadian Veterinary Urolith Centre (1998-2014). Can Vet J., v.57, n.2, p.196-201, 2016.

KAUFMANN, C.; NEVES, R. C.; HABERMANN, J. C. A.. Doença do trato urinário inferior dos felinos. Anuário da Produção Científica dos Cursos de Pós-Graduação, v.4, p.193-214, 2011.

KIRK, C. A.; LING, G. V.; FRANTI, C. E.; SCARLETT, J. M. Evaluation of factors associated with development of calcium oxalate urolithiasis in cats. J Am Vet Med Assoc., v.207, n.11, p.1429-34, 1995.

KOEHLER, L. A.; OSBORNE, C. A.; BUETTNER, M. T.; LULICH, J. P.; BEHNKE, R.. Canine urolithiasis: frequently asked questions and their answers. Veterinary Clinics of North America. Small Animal practice, v.39, n.1, p.161-181, 2008.

LANGSTON, C.; GISSELMAN, K.; PALMA, D.; MCCUE, J. Diagnosis of urolithiasis. Compendium on Continuing Education for the Practising Veterinarian, v.30, n.8, p.447450, 2008.

LANGSTON, C.; GISSELMAN, K.; PALMA, D.; MCCUE, J. Methods of urolith removal. Compendium on Continuing Education for the Practising Veterinarian, v.32, n.6, p.1-7, 2010.

LEKCHAROENSUK, C.; LULICH, J. P.; OSBORNE, C. A.; KOEHLER, L. A.; URLICH, L. K.; CARPENTER, K. A.; SWANSON, L. L. Association between patient-related factors and risk of calcium oxalate and magnesium ammonium phosphate urolithiasis in cats. J Am Vet Med Assoc., v.217, n.4, p.520$525,2000$.

LEKCHAROENSUK, C.; OSBORNE, C. A.; LULICH, J. P. Epidemiologic study of risk factors for lower urinary tract diseases in cats. J Am Vet Med Assoc., v.218, n.9, p.14291435, 2001. 
LEKCHAROENSUK, C.; OSBORNE, C. A.; LULICH, J. P.; PUSOONTHORNTHUM, R.; KIRK, C. A.; ULRICH, L. K.; KOEHLER, L. A.; CARPENTER, K. A.; SWANSON, L. L. Association between dietary factors and calcium oxalate and magnesium ammonium phosphate urolithiasis in cats. J Am Vet Med Assoc., v.219, n.9, p.1228-1237, 2001.

LULICH, J. P.; ADAMS, L. G.; GRANT, D.; ALBASAN, H.; OSBORNE, C. A.. Changing paradigms in the treatment of uroliths by lithotripsy. Veterinary Clinics of North America: Small Animal Practice, v.39, n.1, p.143-160, 2009.

LULICH, J. P.; OSBORNE, C. A.; ALBASAN, H. Canine and feline urolithiasis: diagnosis, treatment, and prevention. In: BARTGES, J.; POLZIN, D. J.. Nephrology and urology of small animals. West Sussex: Wiley-Blackwell, 2011.

LULICH, J. P.; KRUGER, J. M.; MACLEAY, J. M.; MERRILLS, J. M.; PAETAUROBINSON, I.; ALBASAN, H.; OSBORNE, C. A.. Efficacy of two commercially available, low-magnesium, urine-acidifying dry foods for the dissolution of struvite uroliths in cats. Journal of the American Veterinary Association, v.243, n.8, p.1147-1153, 2013.

LULICH, J. P.; BERENT, A. C.; ADAMS, L. G.; WESTROPP, J. L.; BARTGES, J. W.; OSBORNE, C. A. ACVIM small animal consensus recommendations on the treatment and prevention of uroliths in dogs and cats. Journal of Veterinary Internal Medicine, v.30, n.5, p.1564-1574, 2016.

MCCUE, J.; LANGSTON, C.; PALMA, D.; GISSELMAN, K. Urate urolithiasis. Comp Cont Educ Vet., v.31, n.10, p.468-475, 2001.

MESTRINHO, L. A.; GONCALVES, T.; PARREIRA, P. B.; NIZA, M. M.; HAMAIDE, A. J. Xanthine urolithiasis causing bilateral ureteral obstruction in a 10-month-old cat. J Feline Med Surg., v.15, n.10, p.911-916, 2013.

MIDKIFF, A. M.; CHEW, D. J.; RANDOLPH, J. F.; CENTER, S. A.; DIBARTOLA, S. P.. Idiopathic hypercalcemia in cats. J Vet Intern Med., v.14, n.6, p.619-626, 2000.

MOORE, A.. Quantitative analysis of urinary calculi in dogs and cats. Veterinary Focus, p.22-27, 2007.

OKAFOR, C. C.; LEFEVBRE, S. L.; PEARL, D. L.; YANG, M.; WANG, M.; BLOIS, S. L.; LUND, E. M.; DEWEY, C. E. Risk factors associated with calcium oxalate urolithiasis in dogs evaluated at general care veterinary hospitals in the United States. Preventive Veterinary Medicine. Amsterdam, v. 115, n.4, p.217-227, 2014

OSBORNE, C. A.; LULICH, J. P.; BARTGES, J. W.; UNGER, L. K.; THUMCHAI, R.; KOEHLER, L. A.; BIRD, K. A.; FELICE, L. J. Canine and feline urolithiases: relationship of etiopathogenesis to treatment and prevention. In: OSBORNE C. A; FINCO, D. R.. Canine and feline nephrology and urology. Williams \& Wilkins; 1995.

OSBORNE, C. A.; LULICH J. P.; KRUGER J. M.; ULRICH L. K.; KOEHLER L. A. Analysis of 451,891 canine uroliths, feline uroliths, and feline urethral plugs from 1981 to 2007 : perspectives from the Minnesota Urolith Center. Vet Clin North Am Small Anim Pract., v.39, n.1, p.183-197, 2009.

OSBORNE, C.A.; LULICH, J.P.; FORRESTER, D.; ALBASAN, H. Paradigm changes in the role of nutrition for the management of canine and feline urolithiasis. Veterinary
Clinics of North America: Small Animal Practice, v.39, n.1, p. 127-141, 2009.

OSBORNE, C. A.; LULICH, J. P.; SWANSON, L. L.; ALBASAN, H Drug-induced urolithiasis. Vet Clin North Am Small Anim Pract., v.39, n.1, p.55-63, 2009.

PALACIN, M.; GOODYER, P.; NUNES, V.; GASPARINI, P. Cystinuria. In: VALLE, D.; VOGELSTEIN, B.; KINZLER, K. W.; ANTONARAKIS, S. E.; BALLABIO, A.; GIBSON, K. M.. The Online Metabolic and Molecular Bases of Inherited Disease. New York: McGraw-Hill Medical, 2013.

PALM, C.; WESTROPP, J. Cats and calcium oxalate: strategies for managing lower and upper tract stone disease. Journal of Feline Medicine Surgery, v.13, n.9, p.651-660, 2011.

PALMA, D.; LANGSTON, C.; GISSELMAN, K.; MCCUE, J. Feline struvite urolithiasis. Comp Cont Educ Vet., v. 31, n.12, p.1-7, 2009.

PICAVET, P.; DETILLEUX, J.; VERSCHUREN, S.; SPARKES, A.; LULICH, J.; OSBORNE, C.; ISTASSE, L.; DIEZ, M. Analysis of 4495 canine and feline uroliths in the Benelux. A retrospective study: 1994-2004. J Anim Physiol Anim Nutr., v.91, n.5, p.247-251, 2007.

RADITIC, D. M.. Complementary and integrative therapies for lower urinary tract diseases. Veterinary Clinics of North America: Small Animal Practice, v.45, n.4, p. 857-878, 2015.

RATKALKAR, V. N.; KLEINMAN, J. G. Mechanisms of stone formation. Clin Rev Bone Miner Metab., v.9, n.3, p.187-197, 2011.

ROUDEBUSH, P.; FORRESTER, S. D.; PADGELEK, T. What is the evidence? Therapeutic foods to treat struvite uroliths in cats instead of surgery. J Am Vet Med Assoc., v.236, n.9, p.965966, 2010.

SENIOR, D. F.; FINLAYSON, B. 1986. Initiation and growth of uroliths. The Veterinary Clinics of North America. Small Animal Practice, v.16, p.19-26, 2010.

SINGH, S. K.; AGARWAL, M. M.; SHARMA, S. Medical therapy for calculus disease. British Journal of Urology International, v.107, n.3, p.356-368, 2011.

STURGESS, K..Dietary management of canine urolithiasis. In Practice, v.31, p.306-312, 2009.

THUMCHAI, R.; LULICH, J.; OSBORNE, C. A.; KING, V. L.; LUND, E. M.; MARSH, W. E.; ULRICH, L. K.; KOEHLER, L. A.; BIRD, K. A. Epizootiologic evaluation of urolithiasis in cats: 3,498 cases (1982-1992). J Am Vet Med Assoc., v.208, n.4, p.547-551, 1996.

TION, M. T.; DVORSKA, J.; SAGANUWAN, S. A. A review on urolithiasis in dogs and cats. Bulg J Vet Med., v.18, n.1, p.118,2015

ULRICH, L. K.; OSBORNE, C. A.; COKLEY, A.; LULICH, J. P. Changing paradigms in the frequency and management of canine compound uroliths. Vet Clin North Am Small Anim Pract.; v.39, n.1, p.41-53, 2009.

WEBB, J. A.; ROSATI, M.; NAIGAMWALLA, D. Z.; DEFARGES, $A$. The use of medetomidine-based sedation protocols to perform urohydropropulsion and cystoscopy in the dog. The Canadian Veterinary Journal, v.55, n.1, p.1213-1218, 2014.

A CBPC - Companhia Brasileira de Produção Científica (CNPJ: 11.221.422/0001-03) detém os direitos materiais desta publicação. Os direitos referem-se à publicação do trabalho em qualquer parte do mundo, incluindo os direitos às renovações, expansões e disseminações da contribuição, bem como outros direitos subsidiários. Todos os trabalhos publicados eletronicamente poderão posteriormente ser publicados em coletâneas impressas sob coordenação da Sustenere Publishing, da Companhia Brasileira de Produção Científica e seus parceiros autorizados. Os (as) autores (as) preservam os direitos autorais, mas não têm permissão para a publicação da contribuição em outro meio, impresso ou digital, em português ou em tradução. 